\section{Diffuse Idiopathic Skeletal Hyperostosis in the Third Millennium: Is There (Yet) Cause for Concern?}

\section{To the Editor:}

I read with great interest the recent editorial on diffuse idiopathic skeletal hyperostosis (DISH) by Dr. Mader ${ }^{1}$. The author affirms the clinical relevance of this skeletal disorder because of its various complications, some of which are very important in clinical practice (e.g., dysphagia, spinal fracture, spinal lumbar stenosis, neurologic complications, postsurgical heterotopic ossifications, etc). He also emphasizes the need of updating diagnostic criteria (at least 3 sets are used) to obtain a more accurate and timely diagnosis of this condition in its early phases. Dr. Mader is to be congratulated for his interesting paper; however, while defining the still insufficient current diagnostic criteria, he omits comment on possible explanations for this critical diagnostic phase. I would like to express some considerations on the causes of the limited availability of diagnostic tools for DISH.

Forestier's disease, a common name for DISH, particularly in European countries of Latin origin, is an ancient skeletal disorder whose pathologic alterations were described in human skeletons going back to 5000 years ago ${ }^{2}$.

Many names have been proposed for this condition in the last century (Table 1) and this historical aspect may account for the difficulty in defining the disorder, and its nosographic placement among the various rheumatic diseases! The term diffuse idiopathic skeletal hyperostosis (and its famous acronym DISH), proposed by Resnick, et al in $1975^{3}$, is largely accepted by the international scientific community because it more exactly expresses the widespread nature of the disorder and, unfortunately, also our ignorance about its etiology. DISH is a mysterious and fascinating condition; however, it remains a little more neglected in clinical practice and research for several reasons.

First, although common in middle-aged and elderly patients, especially those with metabolic disorders, DISH is still underdiagnosed. In their magistral description Forestier and Rotes-Querol considered DISH "as a not rare disease but most often either goes unnoticed or is mistaken for some other form of vertebral ossification" 4 . More than 30 years ago Resnick included DISH among the disorders that are "lesser known, poorly recognized or misunderstood" ": Is it possible that these statements are still relevant today? In my clinical practice I continue to see many patients with DISH misdiagnosed as having osteoarthritis (OA), and I am regularly asked to differentiate DISH from ankylosing spondylitis (AS). Resnick's criteria are useful for separating DISH from spondylosis deformans and AS, but they don't help us to evaluate DISH in its early phases and/or with extraspinal alterations; the criteria consider absence of sacroiliac (SI) joint involvement as a differentiating aspect versus AS. In recent decades many authors have emphasized difficulty in the differential diagnosis between these 2 conditions with special reference to SI joint abnormalities occurring in old age, which could simulate intraarticular bone fusion on frontal radiographs ${ }^{6,7}$. The importance of com-

Table 1. Synonyms for Forestier's disease.

Spondylitis deformans (Knaggs, 1925)

Spondylitis ossificans ligamentosa (Oppenheimer, 1942)

Senile ankylosing hyperostosis of the spine (Forestier and Rotes-Querol, 1950)

Spondylosis hyperostotica (Ott, 1953)

Physiologic vertebral ligamentous calcification (Smith, 1955)

Generalized juxtaarticular ossifications of ligaments of the vertebral column and of the ligamentous and tendinous tissues of the extremities (Sutro, 1956)

Vertebral hyperostosing discosomatic osteoarthritis (Biressi and Mussa, 1957) Ankylosing hyperostosis (Bywaters, 1967)

Metabolic hyperostotic spondylopathy (Giordano, 1975)

Diffuse idiopathic skeletal hyperostosis (Resnick, 1975)

Diffuse enthesopathic hyperostosis (Lagier and Baud, 1978)
Table 2. Number of articles published on osteoarthritis versus DISH, as cited on PubMed.

\begin{tabular}{lcc}
\hline Period of Publication & Osteoarthritis & DISH \\
\hline $01 / 01 / 1979$ to $01 / 01 / 1989$ & 4849 & 139 \\
$01 / 01 / 1989$ to $01 / 01 / 1999$ & 8699 & 233 \\
$01 / 01 / 1999$ to $01 / 01 / 2009$ & 18487 & 218 \\
\hline
\end{tabular}

puted tomography for resolving this diagnostic aspect has been stressed ${ }^{7}$, and other researchers have described a midthoracic notch in DISH but not in patients with AS; moreover, a more accurate evaluation of zygoapophyseal joints as an additional has been suggested ${ }^{8,9}$.

Second, since Forestier's and Rotes-Querol's description in $1950^{4}$, DISH has been considered an entity of little clinical relevance, and diagnosis is often made by radiographic examination prescribed for another clinical condition. Because of its mild clinical manifestations for which drug use is rarely required ${ }^{4}$, no clinical trial has ever been done, and no drug has shown to be efficacious in preventing or curing this condition ${ }^{10}$.

Third, as is well known, a disease is regarded by research with particular attention because of its clinical and epidemiological relevance and emotional impact on public opinion. DISH, much more than other rheumatic diseases, has not seemed to fit these characteristics.

Lastly, being considered a variant form of $\mathrm{OA}^{11,12}$, this degenerative disorder has come to be of less research interest than in the past. While in recent decades OA obtained much more attention from researchers, that was not the case for DISH (Table 2).

Is there still concern for this ancient disorder in the third millennium? Would it be too much to hope for more accurate diagnostic criteria in the future as invoked in Dr. Mader's editorial? I think the answer to both questions will be affirmative. In the meantime it has become clear that this condition is a distinct clinical entity ${ }^{13-15}$ with many serious manifestations. This emerging aspect should stimulate much more interest among researchers than in the past. Every effort should be made for close collaboration among investigators from every field (endocrinology, orthopedics, pathology, radiology, rheumatology, etc.) interested in the disorder. This common effort should also translate into expanded knowledge and recognition of the disorder outside the borders of rheumatology.

In the digital age, with availability of ever more innovative and complex technologies, it should not be difficult to arrive at defining new criteria for a timely clinical-radiologic evaluation leading to diagnosis of DISH in its early phases.

FLORINDO VERDONE, MD, Rheumatologist, Pharmacologist, Azienda Sanitaria Locale TO2 - Torino Nord, Lungo Dora Savona 24, 10152 Torino, Italy. E-mail: f.verdone@alice.it

\section{REFERENCES}

1. Mader R. Diffuse idiopathic skeletal hyperostosis: Time for a change. J Rheumatol 2008;35:377-9.

2. Rogers J, Watt I, Dieppe P. Paleopathology of osteophytosis, vertebral ankylosis, ankylosing spondylitis and vertebral hyperostosis. Ann Rheum Dis 1985;44:113-20.

3. Resnick D, Shaul SR, Robins SM. Diffuse idiopathic skeletal hyperostosis (DISH): Forestier's disease with extraspinal manifestations. Radiology 1975;115:513-24.

4. Forestier J, Rotes-Querol J. Senile ankylosing hyperostosis of the spine. Ann Rheum Dis 1950;9:321-30.

5. Resnick D. Disorders of the axial skeleton which are lesser known, poorly recognized or misunderstood. Bull Rheum Dis 1977;28:932-9.

6. Weisz GM, Green L. Progressive obliteration in Forestier's disease. Int Orthop 1986;27:47-51.

7. Yagan R, Khan MA. Confusion of roengenographic differential diagnosis between ankylosing hyperostosis (Forestier's disease) 
and ankylosing spondylitis. Clin Rheumatol 1983;2:285-92.

8. Maertens M, Mielants H, Verstraete K, Veys EM. Evaluation of the involvement of axial entheses and sacroiliac joints in relation to diagnosis: comparison among diffuse idiopathic skeletal hyperostosis (DISH), osteoathrosis and ankylosing spondylitis. Clin Rheumatol 1992;11:551-7.

9. De Vlam K, Mielants H, Veys EM. Association between ankylosing spondylitis and diffuse idiopathic skeletal hyperostosis: reality or fiction? Clin Exp Rheumatol 1996;14:5-8.

10. Mader R. Current therapeutic options in the management of diffuse idiopathic skeletal hyperostosis. Expert Opin Pharmacother 2005;6:1313-6.

11. Ott VR. Uber die spondylosis hyperostotica. Schweiz Med Wochenschr 1953;83:790-9.
12. Moskowitz RW. Clinical and laboratory findings in osteoarthritis. In: McCarthy DJ, Koopman WJ. Arthritis and allied conditions. Philadelphia: Lea \& Febiger 1993:1735-60.

13. Denko CW, Boja B, Moskowitz RW. Growth promoting peptides in osteoarthritis and diffuse idiopathic skeletal hyperostosis-insulin, insulin-like growth factor-1, growth hormone. J Rheumatol 1994;21:1725-30.

14. Kiss C, Szilagyi M, Paksy A, Poòr G. Risk factors for diffuse idiopathic skeletal hyperostosis: a case-control study. Rheumatology 2002;41:27-30.

15. Mader R. Diffuse idiopathic skeletal hyperostosis: a distinct clinical entity. Isr Med Ass J 2003;5:506-8.

J Rheumatol 2010;37:6; doi:10.3899/jrheum.100097 